\title{
Los límites de la voluntad y el derecho a la vida (Breve comentario al Dictamen del Consejo Consultivo de Andalucía 90/2007, de 27 de febrero) ${ }^{1}$
}

\author{
Alberto Anguita Susi \\ Prof. de Derecho Constitucional \\ Universidad de Jaén
}

\section{PREMISA: EL OBJETO DEL DICTAMEN ${ }^{2}$}

El Dictamen del Consejo Consultivo versa sobre una consulta planteada por la Consejera de Salud de la Junta de Andalucía en relación a la petición formulada por una paciente que desea la suspensión del tratamiento con ventilación mecánica que viene recibiendo en los últimos años en un centro hospitalario andaluz; suspensión que le conducirá, inevitablemente, a la muerte debido al avanzado e irreversible estado de la enfermedad muscular que padece ${ }^{3}$.

En el expediente del caso obra, asimismo, el Informe de la Comisión Autonómica de Ética e Investigación Sanitarias de Andalucía, en el que se establece que la solicitud de la paciente es consecuencia de la revocación del consentimiento previamente emitido para recibir un tratamiento con soporte vital mediante ventilación mecánica. De modo que, según dicha Comisión,

\footnotetext{
${ }^{1}$ Este trabajo se enmarca dentro del Proyecto de Investigación "Principios y derechos constitucionales de la personalidad: su proyección en la legislación civil", cuyo investigador principal es el Prof. D. Gerardo Ruiz-Rico Ruiz, Catedrático de Doㅡ Constitucional de la Universidad de Jaén.

${ }^{2}$ Hemos extraído el contenido del Dictamen de la web: www.juntadeandalucia.es/consejoconsultivo

${ }^{3}$ Véanse los Fundamentos Jurídicos Primero y Segundo, dedicados, respectivamente, a justificar la importancia del tema objeto de estudio y a concretar el significado y alcance del mismo.
} 
constatada la libertad y la firmeza de la decisión tomada, no existirían razones éticas que impidan cumplir la petición de la paciente.

En virtud de lo anterior, la Consejería de Salud de la Junta de Andalucía requiere del Consejo Consultivo que determine, de un lado, si la negativa al tratamiento con ventilación mecánica se ajusta a Derecho y, de otro, si es jurídicamente punible la actuación de los profesionales sanitarios que desconecten el aparato de ventilación mecánica.

\section{LA POSICIÓN DEL CONSEJO CONSULTIVO}

Formulada la consulta en los términos expuestos, el Consejo Consultivo de Andalucía emitió un Dictamen, cuya fundamentación jurídica suscita algunos aspectos que invitan al debate y a la reflexión.

En el Fundamento Jurídico Tercero del Dictamen se enfatiza la importancia constitucional que tiene el derecho a la vida, si bien resulta curioso que se utilice como argumento el contenido de la STC 120/1990, relativa a la huelga de hambre de los GRAPO, dado que en ésta se mantiene una postura contrapuesta a la decisión finalmente adoptada por el Consejo Consultivo ${ }^{4}$. De hecho, el Dictamen concluye afirmando que "desde la perspectiva de la Constitución Española y del Convenio Europeo de Derechos Humanos, no existe un derecho a morir que forme parte del derecho a la vida (...) y que demande la ayuda de los poderes públicos”.

Por otro lado, el Fundamento Jurídico Cuarto destaca, de acuerdo con la normativa europea, estatal y autonómica vigente, la importancia de la autonomía y la voluntad del paciente a la hora de preservar su dignidad ante intervenciones médico-sanitarias no deseadas. En palabras del Consejo: "Con carácter general se puede afirmar que la manifestación libre de voluntad y el previo consentimiento de pacientes y usuarios se constituyen en la clave de bóveda de cualquier actuación en el ámbito de la sanidad. Así se desprende con claridad del artículo 2.2. de la Ley 41/2002, pero también de otra serie de pre-

\footnotetext{
${ }^{4}$ El Consejo Consultivo hace también mención a la STC 137/1990, en la que se afirma que la libertad de rechazar un tratamiento no cabe encuadrarla dentro del art. $17 \mathrm{CE}$ en cuanto manifestación de la libre autodeterminación de la persona.
} 
ceptos que parten de una misma orientación, destinada a salvaguardar ese principio fundamental' (las cursivas son añadidas) ${ }^{5}$.

Finalmente, el Fundamento Jurídico Quinto está dedicado a determinar si la conducta del personal sanitario que va a desconectar la máquina que mantiene artificialmente la vida de la paciente, puede o no ser considerada punible por la vía del art. 143 del Código Penal. El propio Consejo recuerda que la conducta típica consiste en causar o cooperar activamente con actos necesarios y directos la muerte del paciente, en el caso de que éste se encuentre ante una enfermedad grave que conduciría necesariamente a su muerte, o que le produjera graves padecimientos permanentes y difíciles de soportar.

La impunidad del personal sanitario es defendida por el Dictamen en los siguientes términos: "prácticamente la generalidad de la doctrina penal, excluye en todo caso del tipo la eutanasia pasiva indirecta, en la que el resultado de muerte es fruto de una omisión, en el sentido penal tradicional de $<<$ comisión por omisión $\gg>$. El Consejo culmina la debilidad de su razonamiento afirmando: "Es más, aun en la hipótesis de que la interrupción de la ventilación mecánica no se considere conducta pasiva e indirecta, dichos profesionales estarían exentos de responsabilidad criminal por actuar en cumplimiento de un deber".

\footnotetext{
${ }^{5}$ Como consecuencia de ello, en el Fundamento Jurídico Cuarto del Dictamen puede leerse: "En definitiva, la idea capital subyacente de tal regulación normativa es que las prestaciones sanitarias no se pueden imponer contra la voluntad del paciente consciente y libre que las rechaza, aunque se trate de una situación de riesgo para la vida". De otro lado, no deja de ser llamativo que en el Dictamen se utilice como argumento el hecho de que el art. 11 de la Ley 41/2002, de 14 de noviembre, de autonomía del paciente y de los derechos y obligaciones relativos a la información y a la documentación clínica, establezca como límite al testamento vital la lex artis médica, toda vez que ésta "no significa otra cosa que la aplicación al supuesto concreto de todas las medidas que según los conocimientos del momento y los protocolos médicos resulten aplicables al caso. Sin embargo, es previsible que el documento de instrucciones previas se utilice precisamente para todo lo contrario, esto es, para negar el consentimiento a la aplicación médica de esas determinadas prácticas encaminadas a mantener a toda costa la vida del paciente" (CANTERO MARTÍNEZ J., La autonomía del paciente: del consentimiento informado al testamento vital, Bomarzo, Albacete, 2005, p. 77).

${ }^{6}$ La mayoría de la doctrina, sobre todo penal, entiende que la desconexión de aparatos técnicos es una omisión, dado que el médico se limita a suspender un tratamiento (según el Dictamen, la ventilación mecánica es uno de los soportes que integran un tratamiento médico continuado), constituyendo dichos aparatos una longa manus, una prolongación, de su actividad. Sin embargo, no faltan opiniones en contrario como la de ZUGALDÍA ESPINAR J.M., "Eutanasia y homicidio a petición: situación legislativa y perspectivas político-criminales", en Rev. de la Facultad de Derecho de la Universidad de Granada, no 13, 1987.
} 


\section{UNA VISIÓN ALTERNATIVA AL DICTAMEN}

\section{Los elementos del debate: derecho a la vida y autonomía individual}

Como hemos tenido la oportunidad de comprobar, el Dictamen del Consejo Consultivo tiene como objetivo solucionar el conflicto de valores -voluntas aegroti suprema lex e in dubio pro vitae que caracteriza este tipo de supuestos; y lo hace considerando que la autonomía de la voluntad del paciente debe prevalecer, en todo caso, siempre que ésta se manifieste de manera clara, seria e inequívoca ${ }^{7}$.

Frente a este planteamiento, y con la finalidad de conjugar y ponderar ambos valores ${ }^{8}$, sería conveniente apelar quizás a la denominada "tesis de la disponibilidad vital matizada”, que postula la supremacía del derecho a la vida siempre que ésta sea "digna y de calidad". Como resulta obvio, la puesta en práctica de esta tesis no está exenta de dificultades, habida cuenta de que introduce un parámetro cuyo evidente cariz subjetivo conduce a que nos tengamos que preguntar cuándo puede considerarse indigna o falta de calidad una vida ${ }^{9}$. Todo ello sin olvidar que la dignidad ha sido utilizada "tanto por las posturas preu-

\footnotetext{
${ }^{7}$ Sobre esta cuestión, resulta muy revelador e ilustrativo el trabajo de MARCOS DEL CANO A.M. y DE CASTRO CID B., "Eutanasia y debate sobre la jerarquía de los valores jurídicos", en Rev. Persona y Derecho, no 41, 1999. Y CARBONELL MATEUR J.C., "Constitución, suicidio y eutanasia”, en Cuadernos Jurídicos, nํ10, 1993.

${ }^{8}$ Como indica PRIETO SANCHÍS, "en el mundo del Derecho el resultado de la ponderación no ha de ser necesariamente el equilibrio entre tales intereses, razones o normas; al contrario, lo habitual es que la ponderación desemboque en el triunfo de alguno de ellos en el caso concreto. En cambio, donde sí ha de existir equilibrio en el plano abstracto: en principio, han de ser todos del mismo valor, pues de otro modo no habría nada que ponderar, sencillamente, en caso de conflicto se impondría el de más valor" ("Neoconstitucionalismo y ponderación judicial", en AAVV (Ed. M. Carbonell)., Neoconstitucionalismo(s), Trotta, Madrid, 2003, p. 137). A lo que el mismo autor añade: "se logra sólo una preferencia relativa al caso concreto que no excluye una solución diferente en otro caso; se trata, por tanto, de esa jerarquía móvil que no conduce a la declaración de invalidez de uno de los bienes o valores en conflicto, ni a la formulación de uno de ellos como excepción permanente frente al otro, sino a la preservación abstracta de ambos, por más que inevitablemente ante cada caso de conflicto sea preciso reconocer primacía a uno u otro" (Justicia constitucional y derechos fundamentales, Trotta, Madrid, 2003, p. 191).

${ }^{9}$ F. BACON, en su famosa obra Historia Vitae et Mortis (1623), ya hablaba de facilitar la muerte a los enfermos terminales o desahuciados e incluso de la supresión de vidas desprovistas de valor vital, irrecuperables o socialmente inútiles. Por su parte, H. BIGGS, se refiere a la dignidad como "un valor intrínseco de la persona que comprende un elemento esencial de la autonomía per-
} 
tanásicas, que se justifican en la denominada muerte digna, como de las posturas provida, que hacen referencia a la dignidad del moribundo y del sufriente para oponerse a su eliminación, incluso cuando él mismo la demanda" ${ }^{0}$.

Quizás por ello una solución ecléctica sería la de considerar que toda "persona humana tiene un valor en sí misma que queda fuera del consentimiento humano. Todo sujeto es portador en sí mismo de una Humanidad o Dignidad que él no puede violar con su arbitrio"11. A tenor de esta idea, re-

sonal muy en relación con la calidad de vida del sujeto" (Euthanasia. Death with Dignity and the Law, Oxford-Portland, 2001, p. 145). Para ROVIRA VIÑAS, "la dignidad se identifica con la libertad, concretamente con una libertad práctica, que posibilita y garantiza poder decidir, optar y actuar para ser uno mismo. La dignidad, por tanto, se revela como consecuencia de ejercer la autonomía. En este sentido interno, vivir dignamente es vivir la vida que uno libremente ha elegido" (Autonomía personal y tratamiento médico. Una aproximación constitucional al consentimiento informado, Aranzadi, Pamplona, 2007, p. 54). En sentido contrario cabe citar el caso Claire Conroy, resuelto por una sentencia de 1985 del Tribunal Supremo de Nueva Jersey, en la que se establecía: "Rehusamos de forma expresa autorizar las decisiones basadas en apreciaciones sobre el valor personal, o la utilidad social de la vida de otra persona, o del valor que esa vida tiene para otras personas. No creemos conveniente que el tribunal nombre a una persona para determinar que la vida de otra persona no merece la pena, simplemente porque a la persona autorizada le parezca que la $<<$ calidad de vida $>$ del paciente o su valor social es insignificante. El mero hecho que de que las funciones del paciente sean limitadas o que el pronóstico médico sea negativo, no implica que no pueda disfrutar de lo que le queda de vida ni que la muerte sea la mejor alternativa". Citado por HUMPHRY D. y WICKETT A., El derecho a morir. Comprender la eutanasia, Tusquets, Barcelona, 2005, p. 353.

${ }^{10}$ SERRANO J.M., "Sentencias constitucionales sobre la muerte digna", en Rev. Persona y Derecho, $\mathrm{n}^{\circ}$ 54, 2006. Asimismo, puede verse a SENA P., "Dignidad de la persona: un estudio jurisprudencial”, en Rev. Persona y Derecho, no 41, 1999.

${ }^{11}$ MEGÍAS QUIRÓS J.J., "Dignidad del hombre ante la muerte", en Rev. Persona y Derecho, Sumplemento Humana Iura de derechos humanos, no 4, 1994, p. 122. En el mismo sentido, P. SENA afirma: "la dignidad de la persona equivale a dignidad de toda persona humana, esto es, igualdad radical de todos los seres humanos en cuanto al respeto que merecen en su humanidad; de donde se sigue, como necesaria conclusión, que tal igualdad debe existir también en la titularidad y el ejercicio de todos los derechos que la dignidad fundamenta, esto es, de todos aquellos derechos para cuyo disfrute no se precisa más que la condición de ser humano" ("Dignidad de la persona: un estudio jurisprudencial", op. cit., p. 194).

Desde una perspectiva constitucional, destaca el trabajo de ALEGRE MARTÍNEZ M.A., La dignidad de la persona como fundamento del ordenamiento constitucional español, Secretariado de Publicaciones de la Universidad de León, León, 1996; FERNÁNDEZ-SEGADO Fo., "Dignidad de la persona, orden valorativo y derechos fundamentales en la Constitución española de 1978", en AAVV., Jornadas chilenas de Derecho Público, EDEVAL, Valparaiso, 1995; del mismo autor, "La dignidad de la persona en el ordenamiento constitucional español", en Rev. Vasca de Administración Pública, no 43, 1995; y BATISTA JIMÉNEZ F., "La eficacia del valor dignidad de la persona en el sistema jurídico español", en Cuestiones Constitucionales, Rev. Mexicana de Derecho Constitucional, no 11 . 
sulta evidente que el fundamento último de la eutanasia no se basa únicamente en la voluntad del paciente, sino también en el valor de su vida ${ }^{12}$. La dignidad de la persona, por tanto, puede ser considerada como un punto de partida, dado que consagra la igualdad de los seres humanos, pero también un punto de llegada ligado a la calidad de vida. Esto hace que, posiblemente, fuera conveniente entender que la dignidad de la persona constituye una categoría separada e independiente de la calidad; de hecho, en sentido estricto, no sería acertado hablar de una vida indigna, sino de las condiciones en las que el sujeto titular de la misma se encuentra.

\section{2. ¿Existe un derecho a reivindicar la propia muerte ${ }^{13}$}

Como ya se ha dicho, uno de los principales argumentos que trasciende de la STC 120/1990 es que la libertad, entendida en un sentido amplio, no puede operar como fuente de otros derechos, de manera que no es posible que, al amparo de la misma, quepa defender a partir del derecho a la vida su contrario $^{14}$. Si esto es así, parece evidente que del art. 15 CE no cabe deducir

\footnotetext{
${ }^{12}$ Esta idea ha sido defendida, entre otros muchos autores, por SERRANO RUIZ-CALDERÓN J.M., Eutanasia y vida dependiente, Ediciones Internacionales Universitarias, Madrid, 2001.

${ }^{13}$ Como señala R.G. FREY, "es importante no confundir los debates sobre si la muerte es un derecho constitucional con los debates sobre si es un derecho constitucional recibir ayuda para morir. Si se concluyera que existía el derecho constitucional a morir eso no implicaría la licitud del auxilio médico para morir" ("Distintos tipos de muerte", en AAVV., La Eutanasia y el auxilio médico al suicidio, Cambridge University Press, Madrid, 2000).
}

${ }^{14} \mathrm{Al}$ respecto, resultan ilustrativas las palabras de NÚÑEZ PAZ, según el cual "quien decide quitarse la vida no está renunciando al derecho a la vida, sino a la vida misma que es el prespuesto del derecho, y quien dispone de su vida, por sí mismo o por medio de otro, no renuncia en favor de tercero en cuanto mantiene el dominio del hecho, y por consiguiente el dominio sobre el bien jurídico vida" (Homicidio consentido, eutanasia y derecho a morir con dignidad, Tecnos, Madrid, 1999, p. 288). En esta línea, ROMEO CASABONA entiende que "dadas las especiales características que presenta el derecho a la vida, no cabe distinguir entre $<<$ renuncia al derecho $>>$ y $<<$ renuncia a su ejercicio $\gg>$, pues a diferencia de otros derechos fundamentales en los que cabría su separación, en el de la vida coinciden (...) Quien decide quitarse a sí mismo la vida no está renunciando necesariamente al derecho a la vida, sino a la vida misma, que es el presupuesto material de tal derecho" (El derecho y la bioética ante los límites de la vida humana, Centro de Estudios Ramón Areces, Madrid, 1994, pp. 107 y 108). Sobre esta cuestión ROVIRA VIÑAS considera conveniente distinguir entre el derecho a la vida y el presupuesto biológico de la existencia; de forma que se puede y debe defender la vida humana frente al exterior, pero no se puede regular jurídicamente la existencia (Autonomía personal y tratamiento médico..., op. cit. pp. 118 y 119). 
un derecho a disponer libremente de la vida ${ }^{15}$. En palabras del propio Tribunal Constitucional, la vida no conlleva "un derecho subjetivo que implique la posibilidad de movilizar el apoyo del poder público para vencer la resistencia que se oponga a la voluntad de morir, ni mucho menos, un derechos subjetivo de carácter fundamental en el que esa posibilidad se extienda incluso frente a la resistencia del legislador" 16 .

La rotunda y meridiana claridad de esta declaración eliminaría de raíz cualquier intento de reclamar un derecho a morir frente a terceros ${ }^{17}$, si bien es cierto que las distintas normas autonómicas sobre testamentos vitales o voluntades anticipadas parecen permitir lo contrario ${ }^{18}$. En este sentido, resulta paradigmática la Ley Foral de Navarra 11/2002, de 6 de mayo, sobre los de-

${ }^{15} \mathrm{M}$. ATIENZA ha apuntado que "si aceptamos que el derecho a la vida recogido en la Constitución debe interpretarse en el sentido del primer modelo indicado, entonces tendremos que aceptar también que la Constitución prohíbe toda forma de eutanasia (tanto la no voluntaria como la voluntaria, tanto la activa como la pasiva), en cuanto que la eutanasia presupone, en efecto, que un individuo tiene derecho a morir" (Tras la Justicia, Ariel, Barcelona, 1993, p. 106).

${ }^{16}$ Vid. RUIZ MIGUEL A., "Autonomía individual y derecho a la propia vida (un análisis filosófico-jurídico)", en Rev. del Centro de Estudios Constitucionales, no 14, 1993. La posición del Tribunal Constitucional ha sido seguida, asimismo, por el Tribunal Europeo de Derechos Humanos, quien en el caso Pretty vs. Reino Unido, de 29 de abril de 2002, y amparándose en el art. 2 del Convenio Europeo para la protección de los Derechos Humanos, declaraba que el derecho a la vida no implica el derecho a la muerte, es decir, no crea un derecho a la autodeterminación del sujeto.

El peso de los argumentos empleados tanto por la jurisprudencia constitucional como europea es la causa, probablemente, de que el art. 20 del nuevo Estatuto de Autonomía para Andalucía fuese modificado durante el proceso de elaboración parlamentaria, de manera que si originariamente afirmaba que se "garantiza a todos el derecho a morir dignamente", en su redacción final puede leerse que "tienen derecho a recibir un adecuado tratamiento del dolor y cuidados paliativos integrales y a la plena dignidad en el proceso de muerte".

${ }^{17}$ RUIZ VADILLO afirma al respecto que "el sentido básico de protección a la vida en el Derecho Constitucional, viene referido al propio Estado en el sentido de impedir que se quite la vida a seres humanos o, en definitiva, que se venga a legalizar la muerte a manos de decisiones estatales (...) Por consiguiente, solo de manera indirecta viene a afectar a la disposición sobre la propia vida y a la protección a distintos niveles de la vida respecto a ataques provinientes de otras personas físicas" ("El derecho a la vida y a la integridad física", en AAVV., Los derechos fundamentales y libertades públicas, Vol. I, Ministerio de Justicia, Madrid, 1992, p. 25).

${ }^{18}$ Para tener una visión de conjunto sobre este tema puede verse a LÓPEZ SÁNCHEZ C., Testamento vital y voluntad del paciente (Conforme a la Ley 41/2002, de 14 de noviembre), Dykinson, Madrid, 2003; y REQUERO IBÁÑEZ J.L., "El testamento vital y las voluntades anticipadas: aproximación al ordenamiento español”, en Rev. La Ley, n 5570, 2002. 
rechos del paciente a las voluntades anticipadas, a la información y a la documentación clínica, en cuyo art. 9 prevé que en el documento de voluntad anticipada se pueden incorporar cláusulas para que en el supuesto de situaciones vitales críticas e irreversibles se evite el sufrimiento con medidas paliativas, no se prolongue la vida artificialmente por medio de tecnologías y tratamientos desproporcionados o extraordinarios, ni se atrase abusiva e irracionalmente el proceso de muerte.

A la vista de esta regulación sería factible defender el rechazo a la prolongación artificial de la vida ${ }^{19}$; sin embargo, una cosa es negarse a recibir un tratamiento médico, pese al riesgo de morir, y otra muy distinta que un enfermo pueda reivindicar que le desconecten los soportes artificiales que lo mantienen vivo, dado que ello requeriría la cooperación o asistencia de terceros para provocar la muerte ${ }^{20}$. En este sentido se pronuncia, precisamente, el consejero Sr. Sánchez Galiana en su voto particular al Dictamen"21: "una cosa es dignificar el final de la vida y otra muy distinta avalar la autonomía del paciente para decidir el momento en que (...) desee deliberadamente morir con ayuda sanitaria (...) La retirada de un $<<$ soporte vital $>>$ como el respirador no supone realmente la limitación de un tratamiento o la $<<$ limitación de esfuerzos terapéuticos $>>$, términos éstos últimos que ni siquiera son acuñados por la Ley $41 / 2000$, sino la directa e inmediata causación de la muerte". En consecuencia con estos argumentos, el voto disidente concluye que se ha cometido un homicidio consentido previsto en el art. 143.4 del Código Penal ${ }^{22}$.

${ }^{19}$ El juez Duport, titular de un juzgado de Quebec, decidió en enero de 1992 que los individuos que no pueden ser calificados de moribundos tienen, no obstante, el derecho a solicitar que se interrumpan los soportes vitales, si consideran que la vida les resulta intolerable en dichas circunstancias. Citado por DWORKIN R., El dominio de la vida. Una discusión acerca del aborto, la eutanasia y la lilbertad individual, Ariel, Barcelona, 1998, p. 240.

${ }^{20}$ Sobre los distintos aspectos jurídicos y problemáticos que presenta este tema puede verse a NÚÑEZ PAZ M.A., Homicidio consentido, eutanasia y derecho a morir con dignidad, op. cit.; y AAVV., Decisiones al final de la vida, Ministerio de Sanidad y Consumo-Consejo General del Poder Judicial, Colección Estudios de Derecho Judicial, noำ 15, Madrid, 1998.

${ }^{21}$ Voto particular formulado al amparo del art. 23 de la Ley 4/2005, de 8 de abril, del Consejo Consultivo de Andalucía, y de los arts. 22.1 a) y 60.3 del Reglamento Orgánico de esta Institución.

${ }^{22}$ NÚÑEZ PAZ afirma que este precepto está haciento referencia a un homicidio consentido y no a una simple participación en un suicido, dado que "la conducta supone el causar o cooperar a la muerte de otro, mientras que en el suicidio se trata de la muerte propia. Así pues, en el art. 143.3 se sanciona el homicidio de un suicida, pero no un suicidio" (Homicidio consentido, eutanasia y derecho a morir con dignidad, op. cit. p. 154). 


\section{3. ¿Cuál es el alcance de la voluntad del paciente en las relaciones médico-sa- nitarias?}

El reconocimiento constitucional del derecho a la vida como un derecho fundamental de la persona ha supuesto un giro radical de la posición del paciente respecto a los tratamientos médicos que éste puede recibir a lo largo de su existencia. Así, frente a una concepción paternalista de la medicina, más propia de la tradición hipocrática y sustentada en el principio de beneficiencia, en la que la iniciativa del médico primaba frente a la voluntad del paciente ${ }^{23}$, desde mediados del siglo XX se ha ido abriendo paso el principio de autonomía, en virtud del cual habrá que atender al juicio de valores propio de cada individuo, en función de sus ideales, creencias y proyecto de vida ${ }^{24}$.

Esta inexorable tendencia no significa, sin embargo, que la autonomía o voluntad del paciente deba primar incondicionalmente, sino que éste debe recibir el tratamiento convenido y consentido, previa información facultativa, sin que el mismo pueda ser alterado unilateralmente a no ser que exista una causa médica o una situación de necesidad y urgencia. O lo que es lo mismo, la fórmula en la que se conjuga la relación entre el médico y el paciente es el consentimiento informado ${ }^{25}$, que va a permitir al enfermo la

\footnotetext{
${ }^{23}$ Esta práctica se basaba en la creencia de que una persona enferma no era capaz de tomar una decisión objetiva y libre sobre el tratamiento que mejor le convenía. De hecho, etimológicamente la palabra enfermo proviene de infirmus, que significa sin firmeza y débil, no sólo en lo físico sino también en lo moral o espiritual. En consecuencia, era obvio que el médico actuara como si fuera el tutor del paciente.

24 FERNÁNDEZ BERMEJO M., "Autonomía personal y tratamiento médico: límites constitucionales de la intervención del Estado", en Actualidad Jurídica Aranzadi, nํㅜ132, 1994; LÓPEZ CALERA N., "La vida y la muerte ante la ética y el Derecho. Paternalismo médico y desarrollo científico", en Doxa, nºs 15-16, 1994; y GALÁN CORTÉS J.C., Responsabilidad médica y consentimiento informado, Civitas, Madrid, 2001, pp. 43 a 72.

${ }^{25}$ Entre los trabajos científicos sobre el tema destacamos los siguientes: CANTERO MARTÍNEZ J., La autonomía del paciente: del consentimiento informado al testamento vital, op. cit.; AAVV (Coords. M. Palomares Bayo y J. López y García de la Serna)., El consentimiento informado en la práctica médica y el testamento vital, Comares, Granada, 2002; PULIDO QUECEDO M., "El consentimiento informado en materia de salud: ¿derecho humano fundamental?", en Repertorio del Tribunal Constitucional, 2001; GALÁN CORTÉS J.C., Responsabilidad médica y consentimiento informado, op. cit.; BERROCAL LANZAROT A.I., "La autonomía del individuo en el ámbito sanitario.
} 
posibilidad de pronunciarse en torno a las decisiones médicas que le incumben $^{26}$.

En este contexto, no parece de recibo sacralizar, como hace el Dictamen del Consejo Consultivo, el principio de autonomía hasta el punto de permitir que la voluntad del paciente deba ser respetada, cualquiera que sea su contenido y con independencia de las circustancias en las que se emite. Y es que, si bien en la órbita de los países europeos occidentales se ha avanzado a la hora de reconocer el derecho a la autonomía del paciente, no cabe olvidar que este derecho, como el resto, no tiene un carácter absoluto, de modo que no puede ser utilizado para anular su contenido ${ }^{27}$. Como decía Kant, la voluntad de morir es contraria a la propia racionalidad, en la medida en que no es una manifestación de un sujeto autónomo sino de una persona desesperada por su situación y, en cierto modo, condicionada por la voluntad y experiencia del médico ${ }^{28}$.

El deber de información y el consentimiento informado como derechos del paciente en la nueva Ley 41/2002, de 14 de noviembre”, en Foro. Revista de Ciencias Sociales y Jurídicas, nº 0, 2004; ROVIRA VIÑAS A., Autonomía personal y tratamiento médico..., op. cit.

${ }^{26} \mathrm{El}$ art. 3 de la Ley 41/2002, de 14 de noviembre, de autonomía del paciente y de los derechos y obligaciones relativos a la información y a la documentación clínica, inspirada en el conocido Convenio de Oviedo de 1997, determina que el consentimiento informado es "la conformidad libre, voluntaria y consciente de un paciente, manifestada en el pleno uso de sus facultades después de recibir información adecuada, para que tenga lugar una actuación que afecta a su salud".

${ }^{27}$ En la misma línea, Unamuno consideraba que el individualismo radical no es otra cosa que un desprecio absoluto a la individualidad humana. Esto significa, en definitiva, que el "liberalismo ideológico" puede conducir a una suerte de "individualismo extremo", dado que la autonomía y libertad individual ha evolucionado, en el contexto de las actuales sociedades, a una radicalización de lo individual. Bajo esta tendencia, "la muerte lo que hace es permitir al sujeto escapar del control del Derecho (...) Si un hombre está dispuesto a morir es entonces más poderoso que cualquier Estado. De ahí que el miedo a la muerte haya de ser socializado y la disposición de la propia vida haya de ser perseguida jurídicamente" (PELAYO GONZÁLEZ-TORRE A., La intervención jurídica de la actividad médica: el consentimiento informado, Dykinson, Madrid, 1997, p. 51). Sobre esta cuestión, resultan interesantes, asimismo, los trabajos de RECUERO J.R., La eutanasia en la encrucijada. El sentido de la vida y de la muerte, Biblioteca Nueva, Madrid, 2004; y SCALISI A., Il valore della persona nel sistema e i nuovi diritti della personalità, Giuffrè, Milano, 1990.

${ }^{28}$ En palabras de PELAYO GONZÁLEZ-TORRE A. "El de la enfermedad es un ámbito marcado por la necesidad y el fatalismo. La hipertrofia del lenguaje de la libertad lleva a hablar de autonomía y consentimiento también en la relación médica, haciendo pensar que el enfermo puede decidir de forma libre y consciente, pero hay que reconocer también que estos principios no 
Estos argumentos pueden servirnos, en consecuencia, para reflexionar en torno al verdadero alcance y significado del consentimiento (informado) y de la voluntad del paciente en el ámbito de las relaciones médico-sanitarias. En este sentido, cabría afirmar que "la misión primordial que cumple la idea del consentimiento, una vez adaptada por el derecho a su forma de operar, no es la de funcionar específicamente como defensa de la autonomía del individuo, sino la de actuar como un instrumento jurídico que va a revolucionar la correlación de fuerzas tradicionalmente existente en la relación médico-paciente" ${ }^{29}$. Dicho en otros términos, "la teoría del consentimiento informado produce un desplazamiento del campo de la libertad hacia el campo de la responsabilidad (...) a la vez que contrapesa el equilibrio de poder entre el médico y el enfermo" (las cursivas son añadidas) ${ }^{30}$.

Si a lo anterior se añade que el respirador artificial que mantiene con vida a la paciente no es, propiamente, un tratamiento sino, más bien, una me-

se van a mover en este campo con facilidad" (La intervención jurídica de la actividad médica..., op. cit. p. 91). Sobre el proceso de toma de decisiones y de la autonomía del paciente puede verse a SANLLEHÍ J., "A vueltas con el principio de autonomía”, en AAVV (Comp. M. Casado)., Estudios de Bioética y Derecho, Tirant lo Blanch, Valencia, 2000, pp. 101 a 112; en la misma obra y sobre el mismo tema, consúltese a GARCÍA AZNAR A., "Sobre el respeto a la autonomía de los pacientes", pp. 197 a 212.

En relación a este tema resulta ilustrativo el art. 579.3 del Código Penal italiano, el cual, refiriéndose a la eutanasia afirma que el consentimiento es inválido cuando se presta por una persona que se encuentra en una situación de "deficiencia física", expresión que ha sido entendida por la doctrina mayoritaria como cualquier aminoración intelectual o del poder de crítica, así como de debilidad de las funciones volitivas, lo que comprendería la situación en la que se encuentran los enfermos terminales (Vid. GUADAGNO G., "Riflessioni in tema di eutanasia”, en Rev. Critica penale e medicina legale, 1962, p. 132).

${ }^{29}$ PELAYO GONZÁLEZ-TORRE A., La intervención jurídica de la actividad médica..., op. cit. p. 97. En sentido contrario, A. ROVIRA entiende que el consentimiento informado, además de ser un instrumento de legitimación de la actuación médica, debe funcionar ante todo como un mecanismo de tutela y efectividad del derecho a la libertad y a la autonomía personal en el ámbito sanitario (Autonomía personal y tratamiento médico..., op. cit. pp. 24 y 25).

30 PELAYO GONZÁLEZ-TORRE A., La intervención jurídica de la actividad médica..., op. cit. p. 100. Un poco más atrás, el autor afirmaba, en conexión con esta idea, que "el consentimiento informado habría surgido ante la necesidad de establecer compensaciones económicas por las consecuencias desafortunadas de la actividad médica, más que por cuestiones abstractas relativas a la autonomía individual y al consentimiento" (p. 98). En este mismo sentido, R.G. FREY señala que "la autonomía del enfermo no reduce al médico a un mero instrumento de sus deseos" ("Distintos tipos de muerte”, op. cit. p. 54). 
dida de soporte vital, la teoría de la voluntad del paciente para rechazar tratamientos cae por su propio peso. Con todo, la cuestión radica en deteminar qué es, realmente, lo que solicita la paciente: ¿que le causen la muerte? o ¿que se limite el esfuerzo terapéutico? La contestación a esta segunda cuestión está íntimamente relacionada con la proporcionalidad y los beneficios del respirador para la salud de la paciente. En el caso que nos ocupa, resulta indudable que el respirador constituye el soporte vital necesario para seguir viviendo, de modo que si este sistema fue proporcional durante diez años también lo será en el momento en el que la paciente solicita su retirada. Por lo que respecta a la primera pregunta planteada convendría señalar que el consentimiento de la paciente no debe consistir en una simple manifestación del deseo de morir, sino en una autorización imperativa a que se le provoque la muerte.

\section{4. ¿Existe responsabilidad penal del personal sanitario?}

Tal y como hemos tenido la oportunidad de apuntar anteriormente, el Dictamen llega a la conclusión de que nos encontramos ante un supuesto de eutanasia pasiva indirecta que, consecuentemente, exoneraría de responsabilidad al personal sanitario encargado de la desconexión del respirador artificial que mantiene con vida a la paciente. Como puede observarse, se trata de un supuesto cuya solución dista de ser pacífica, sobre todo porque resulta difícil determinar si la conducta llevada a cabo por dicho personal debe ser considerada, sin más, como omisiva o pasiva ${ }^{31}$.

$\mathrm{Al}$ respecto, cabría apostillar que la conducta del personal médico es responsable causal del resultado producido lo que de entrada conlleva, al menos, una responsabilidad moral, cuya traducción jurídica se plasma en la atenua-

\footnotetext{
${ }^{31}$ Esta postura enlaza con la denominada visión consecuencialista o utilitarista de la ética (entre cuyos representantes se encuentran autores como Singer, Fletcher o Rachels), en virtud de la cual no existiría una diferencia moral intrínseca entre matar y dejar morir; es decir, la decisión de no mantener a un paciente con vida es tan deliberada moralmente como la decisión de acabar con su vida. De tal forma que si dos acciones producen la misma consecuencia son moralmente idénticas. Para un mayor abundamiento, véase a FERNÁNDEZ SUÁREZ J.A., "El derecho a una muerte digna", en AAVV., Los derechos fundamentales y libertades públicas, op. cit., pp. 299 a 313; y a JUANATEY DORADO C., Derecho, suicidio y eutanasia, Ministerio de Justicia e Interior, Madrid, 1994, pp. 318 a 325, para quien "las consecuencias de orden práctico que lleva aparejadas la conducta del que desconecta el reanimador deben establecerse con independencia de que ésta se describa como una acción positiva o como una acción omisiva" (p. 322). Asimismo puede consultarse a BARCARO R. y BECCHI P., "Eutanasia ed etica medica”, en Rev. Politica del Diritto, no 2, 2002.
} 
ción de la pena prevista en el art. 143.4 del Código Penal ${ }^{32}$. Como ha señalado algún autor, "la habitual línea divisoria entre el auxilio médico al suicidio y la eutanasia voluntaria activa puede ponerse en duda de un modo tal que cuestione exactamente lo obtenido, desde un punto de vista moral, al dividir los casos entre aquéllos en los que el médico proporciona los medios para la muerte y aquellos otros en los que retira o no pone los medios para que siga la vida, como resultado de una petición legítima del paciente, que contempla esta retirada u omisión como parte de un plan para morir"33.

En el caso objeto de análisis concurren determinados elementos del tipo penal descrito: existencia de petición expresa, seria e inequívoca ${ }^{34}$, de una enfermedad grave y de padecimientos permanentes y difíciles de soportar, pero ¿existen actos necesarios y directos? Al respecto conviene tener presente que la paciente muere debido a la desconexión y retirada del respirador artificial y no a que tal hecho provoque que la enfermedad que padece siga su curso natural; es decir, si no se hubiera desconectado el aparato no se habría producido la muerte.

En resumidas cuentas, cabe concluir afirmando que si el derecho a la vida no conlleva el derecho a reivindicar la propia muerte, resulta coherente defender que no existe un correlativo deber u obligación de cooperar o causar la muerte amparándose, sin más, en la autonomía y libertad del paciente que lo solicite.

\section{CONSIDERACIONES CONCLUSIVAS}

El referente inexcusable del marco jurídico-constitucional a la hora de ofrecer una "posible solución jurídica" viene a poner de manifiesto que si bien la muerte es un acto individual, el respeto o no por la vida humana es una

\footnotetext{
${ }^{32}$ Véase el análisis de FERNÁNDEZ PANTOJA P., "El auxilio al suicidio en enfermos terminales y eutanasia”, en AAVV., Estudios jurídico-penales sobre genética y biomedicina, Dykinson, Madrid, 2005 , pp. 331 a 350.

${ }^{33}$ FREY R.G., "Distintos tipos de muerte”, op. cit. p. 59.

${ }^{34}$ El Dictamen del Consejo Consultivo, no obstante, recomienda la necesidad de que la paciente renueve su consentimiento y se reafirme, dado que no queda constancia fehaciente de su verdadera intención.
} 
cuestión social. Consecuentemente, si la tutela y salvaguarda del derecho a la vida implica una protección activa por parte del Estado, hasta el punto de alimentar forzosamente a presos, no se entiende por qué en el supuesto analizado se ha seguido un criterio distinto.

El dolor causado por el "tratamiento" al que la paciente estaba sometida no es la causa de su decisión, sino más bien la angustia y la impotencia generada por una situación de sufrimiento personal y deshaucio que fomenta la sensación de "inutilidad", de "carga social" y de "ausencia de sentido" de la propia existencia. Esta aparente "falta de sentido de la vida", espoleada por ciertos sectores sociales, es lo que, precisamente, sirve de soporte al Dictamen analizado para ensalzar la autonomía del paciente y, por ende, su "derecho a no seguir sufriendo", confundiéndo la eutanasia pasiva con la evitación del ensañamiento terapéutico: es decir, se apoya la práctica eutanásica con la intención de defender al paciente frente al encarnizamiento médico y respetar, por tanto, su derecho a rechazar "tratamientos extraordinarios o desproporcionados" 35 .

Frente a esta postura cabría defender que "la penalización -de la eutanasia, se entiende- no es una carga sobre la autonomía de algunos, es una decisión fundamental sobre el tipo de sociedad que pretendemos y es una medida protectora de quienes, aunque están minusvalorados en la ideología dominante, poseen un valor ontológico y social fundamental para la propia constitución de una sociedad moralmente aceptable" 36 . Posiblemente, morir con dignidad sea dar sentido al dolor y al padecimiento hasta el último momento. Pero para ello resulta imprescindible incentivar las curas paliativas y las terapias del dolor, así como crear y garantizar estructuras de asistencia psicológica para los enfermos terminales y sus familiares si los hubiere; en definitiva, un Estado social y democráticamente avanzado tiene la obligación de ofrecer a sus ciudadanos la posibilidad de elegir entre varias opciones sin imponer ninguna.

Es cierto que las prácticas eutanásicas van adquiriendo carta de naturaleza en nuestro sistema jurídico, pero también lo es que casos como el que hemos analizado no deben servir de ariete político e institucional para avalar una "piadosa necesidad" de ayudar a ciertos enfermos.

\footnotetext{
${ }^{35}$ GÓMEZ TOMILLO M., "Tratamientos paliativos e integridad moral en el contexto de la eutanasia activa indirecta”, en Rev. La Ley, nº 6300, 2005.

${ }^{36}$ SERRANO RUIZ-CALDERÓN J.M., Eutanasia y vida dependiente, op. cit. p. 149.
} 